This item was submitted to Loughborough's Research Repository by the author.

Items in Figshare are protected by copyright, with all rights reserved, unless otherwise indicated.

\title{
Promoting choice and control in residential services for people with learning
} disabilities

PLEASE CITE THE PUBLISHED VERSION

PUBLISHER

(C) Taylor and Francis

VERSION

AM (Accepted Manuscript)

LICENCE

CC BY-NC-ND 4.0

\section{REPOSITORY RECORD}

Finlay, W.M.L., Chris Walton, and Charles Antaki. 2019. "Promoting Choice and Control in Residential Services for People with Learning Disabilities". figshare. https://hdl.handle.net/2134/5433. 
This item was submitted to Loughborough's Institutional Repository (https://dspace.lboro.ac.uk/) by the author and is made available under the following Creative Commons Licence conditions.

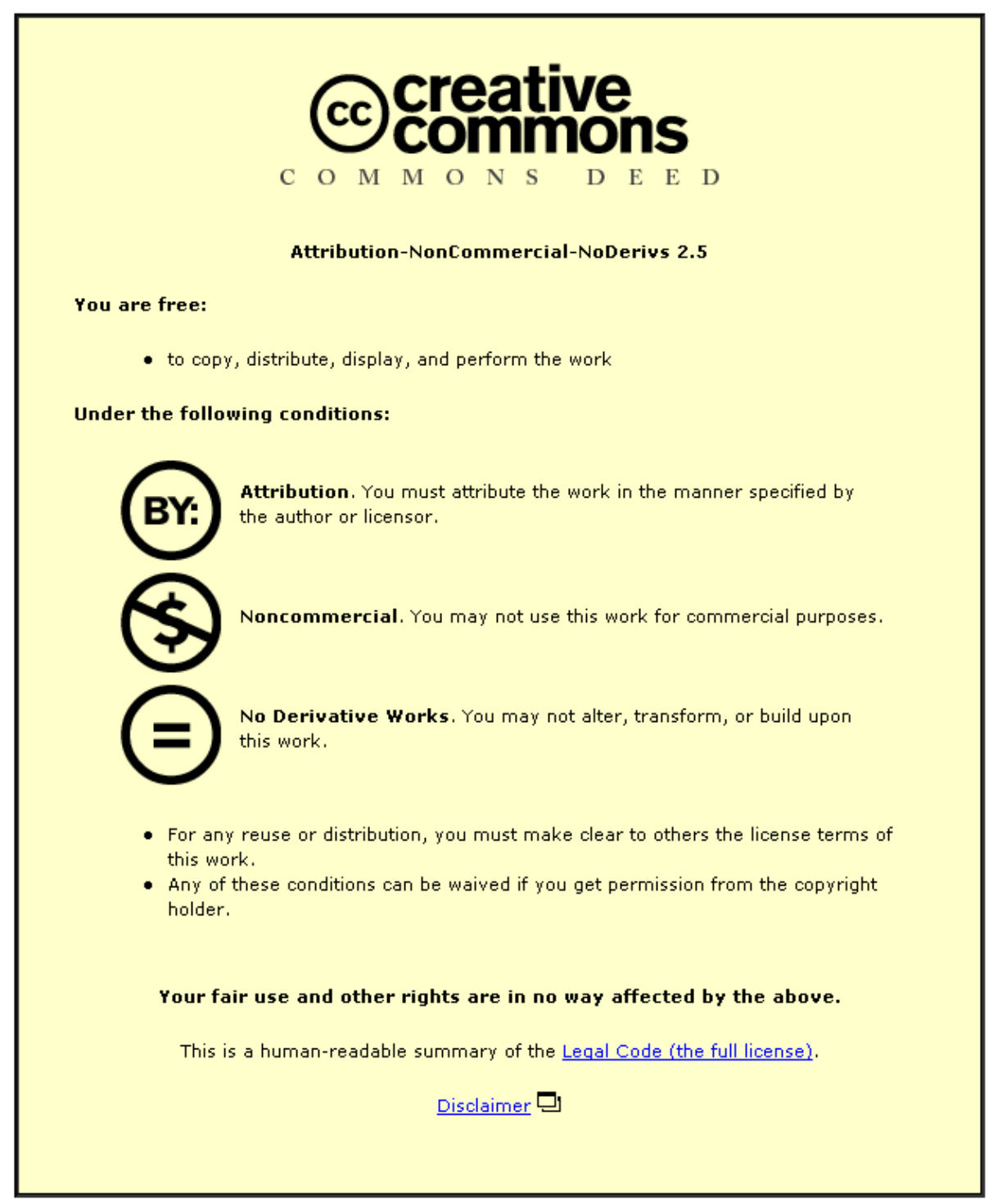

For the full text of this licence, please go to: http://creativecommons.org/licenses/by-nc-nd/2.5/ 
Promoting choice and control in residential services for people with learning disabilities
W.M.L. Finlay ${ }^{1}$
C. Walton ${ }^{2}$
C. Antaki ${ }^{3}$

1 Psychology Dept, University of Surrey, Guildford, Surrey GU2 7XH, w.finlay@surrey.ac.uk*

2 Psychology Dept Lancaster University, Lancaster, LA1 4YF,

c.walton@Lancaster.ac.uk

3 Dept of Social Sciences, Loughborough University, Loughborough LE11 3TU, c.antaki@lboro.ac.uk

*Address for correspondence

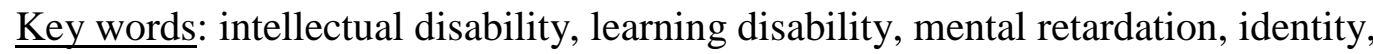
rights, empowerment, choice, control, policy, practice, disempowerment, residential services, staff

The research for this article was funded by ESRC grant number RES-148-25-0002 
Promoting choice and control..

\title{
Promoting choice and control in residential services for people with learning disabilities
}

\begin{abstract}
This paper discusses the gap between policy goals and practice in residential services for people with learning disabilities. Drawing on a nine-month ethnographic study of three residential services, it outlines a range of obstacles to the promotion of choice and control that were routinely observed in the culture and working practices of the services. Issues discussed include conflicting service values and agendas, inspection regimes, an attention to the bigger decisions in a person's life when empowerment could more quickly and effectively be promoted at the level of everyday practice, problems of communication and interpretation, and the pervasiveness of teaching. We offer a range of suggestions as to how these obstacles might be tackled.
\end{abstract}




\section{Promoting choice and control in residential services for people with learning disabilities}

In the UK, recent government policy places the promotion of choice, control and empowerment as a central value for social care services (eg Department of Health, 2005; HM Government, 2005; Prime Minister’s Strategy Unit, 2005; Social Exclusion Unit, 2005). In services for people with learning disabilities, for example, policies have been put in place to encourage empowerment through person-centred planning, direct payments and individual budgets, including service-users in Partnership Boards, increases in the number of advocates, and making sure information is presented in a variety of formats.

However, there are still barriers to the promotion of empowerment in services. The recent report Improving the Life Chances of Disabled People (Prime Minister's Strategy Unit, 2005) discusses two main barriers: supports are often not fitted to the individual, rather disabled people are expected to fit into existing services; and services tend to focus on incapacity, inability and risk, with the result that dependency is created. Indeed, this report identifies a ‘culture of care and dependency’ (p73) in health and social care services, in which those with 'significant cognitive and/or communication impairments are particularly at risk of being denied choice and control in their lives' (p78). The difficulties of translating policy goals of choice and autonomy into practice for people with learning disabilities have been examined by many writers in the field (eg Beamer \& Brookes, 2001; Dowson, 1997; Edge, 2001; Guess, Benson \& Siegel-Causey, 1985; Harris, 2003; Jenkinson, 1993; Jenkinson et al, 1992; Kinsella, 2000; Stalker \& Harris, 1998; Thompson, 2003). This paper discusses obstacles to the promotion of choice and control, drawing on examples from an ethnographic study of three residential services, and offers recommendations as to how these might be overcome.

Interaction as central to empowerment and disempowerment Improving Services, Improving Lives recognizes that the interactions between 'disadvantaged people and frontline staff are crucial to how successful services are in meeting people’s needs' (Social Exclusion Unit, 2005, p57). This is particularly the 
case for those with multiple, complex support needs, who reports have identified as benefiting least from current policy initiatives (HM Government, 2005; Learning Disability Task Force, 2004). Empowerment is not just about choosing to take this type of support rather than that, or providing input into the evaluation and practices of a service in structured situations, but is about what happens between people momentby-moment, in the mundane details of everyday interaction. Power permeates everyday life; it is exercised in the way people talk to each other, in what utterances are taken up and what are ignored, in how and what options are offered, in how information is presented, how spaces are opened up for people to express preferences and how spaces are shut down (Jenkinson, 1993). This is recognized in recent models of supported decision-making, which point out that for many people with learning disabilities, dynamic models of choice which acknowledge the role of sensitive supporters are the most appropriate (eg Beamer \& Brooks, 2001; Edge, 2001; Harris, 2003).

Unfortunately, the ways people have of talking, and the concerns they orient to when they talk to people with learning disabilities, often act counter to the values of choice and control. This is even found in situations in which supporters are attempting to promote empowerment. Our research to date illustrates how power is a dominant feature of interactions between people with learning disabilities and those employed to support them, to such an extent that even in forums set up to provide opportunities for service-users to speak out, subtle interactional dynamics may act to disempower them (e.g., Antaki, Finlay, Sheridan, Jingree \& Walton, 2006; Jingree, Finlay \& Antaki, 2006; Antaki, Young \& Finlay, 2002).

This is acknowledged in official reports: Improving Services, Improving Lives states that disabled people can feel 'steered towards choices made by other people' (Social Exclusion Unit, 2005, p64), in particular, that sometimes staff, managers and parents try to control the lives of people with learning disabilities (Learning Disability Taskforce, 2004). Among other reasons, this is because of imbalances in the skills, knowledge and resources available to the various parties, but also because much information brought to bear on discussions and decisions is mediated by supporters (eg which options are presented as possible, how different outcomes are framed, how practical issues might or might not be overcome). 
We have just completed an intensive, nine-month study of three residential units for people with learning disabilities in which we conducted extended observations, and video-recorded everyday practice. What we find in all of these settings is that what counts as choice and control, when translated into behaviour in real situations, is a complex issue, and staff regularly face difficult dilemmas when attempting to promote these goals. The abstract level of official discourse is not always, or easily, translated into the concrete level of questioning, encouraging, commanding, chiding or coercing (among other ways that staff engage with residents). Empowerment does not flow in any straightforward way from changes in service values, structures, planning or inspection regimes. Certainly there are examples of when staff do promote empowerment, but attention to the details of interaction show us also many ways, often barely even noticed by the actors, in which disempowerment occurs. In some services the obstacles are so widespread as to provide a pervasive climate which frustrates the choice and control agenda. We have grouped these under four main headings: conflicting agendas and inspection regimes; attending to the small things; communication difficulties; and the pervasiveness of teaching.

\section{1) Conflicting Agendas and Inspection Regimes}

Lipsky (1980, described in Hudson, 1993), writing on the dilemmas faced by those at 'street-level' who deliver public services, notes that such workers often have to exercise discretion over how to allocate resources and which service objectives should take priority where they are seen to be conflicting. The decisions and routines of workers, says Lipsky, effectively 'become the public policies they carry out' (1993, p. 382). In services for people with learning disabilities, while choice and control are now put centre stage in government discourse, there are other values and concerns to which staff also orient in their work (Beamer \& Brooks, 2001; Jenkinson et al, 1992). The values promoted through inspection regimes, Care Plans, Health Care and Risk Assessments are often, in practice, contrary to those promoted by the choice agenda. As Beamer and Brooks put it: "Services are important in the lives of many people with high support needs and yet how they are structured and provided is often also part of the problem” (p77; see also Cocks \& Cockram, 1997; Dowson, 1997; Kinsella, 2000; Swift, 2005). While some of these obstacles are the result of informal routines and cultures of working in particular sites (Harris, 2003; Rawlings, Dowse \& 
Shaddock, 1995), others are due to regulatory frameworks, local organisational policy, resources and the existing structure of services (Bannerman et al, 1990; Dowson, 1997; Stancliffe et al, 2000). In both cases, staff are held accountable; in the first case to fellow workers, in the second to management.

This conflict is recognized in the recent Green Paper on social care, Independence, Well-Being and Choice, which acknowledges the need for a debate about managing issues of choice against the protection of vulnerable adults such that choice is not invariably sacrificed to the goal of protecting individuals from risk (DH, 2005; see Beamer \& Brooks, 2001 and Guess et al, 1985 for discussions of this issue). But risk is not the only agenda that might conflict with goals of choice and empowerment, and the Green Paper recognizes that staff can be under pressure from several different directions.

Conflicting values are linked to the different roles staff manage. For example, in one service for people with multiple and profound impairments in our study, being a competent team-member seemed to involve making sure the residents had all eaten and gone to the toilet before the next shift came on, and making sure the house was clean and the laundry done. These priorities are not difficult to understand if we recognize that an unannounced visit by a relative or manager is more likely to lead to a complaint about lack of cleanliness than to a challenge over whether residents' preferences had been respected earlier in the day. The former is immediately visible; the latter is not. In this service, cleanliness and routine seemed to be the primary concerns for the staff, even taking precedence over engaging with the residents in either a social or task-based manner (see Puddicombe, 1995, for a discussion of this issue). In this home, most staff members would also not routinely encourage residents to participate in the preparation of their meals; in part because of fears over food 'hygiene' and in part because they saw the residents as lacking the skills required.

There are other role conflicts, of course. Being a good keyworker may involve liasing with family members, who have their own views which might run contrary to the preference of the person with learning disabilities. Being a good employee may involve making sure an agenda is pursued in a meeting in a reasonable amount of time, making sure other residents are not disturbed, making sure a person adheres to 
health or dietary plans, making sure the rules (or routines) of the house are upheld, the health and safety procedures not violated, and so on. Staff are also representatives of their profession or employing organisation, and, in line with this, we have observed staff deflecting criticism of other workers or service structures by offering residents rationalizations or by simply ignoring such complaints (eg Antaki et al, 2002). For example, in one assessment unit we observed a man repeatedly complain about the length of time his care manager was taking to arrange a new residential placement, and the difficulty he faced when trying to contact the person, who rarely returned his calls. This was a real source of frustration since the man was not only effectively excluded from the process of searching for a new home, but he had no idea of the time he would have to wait in the assessment unit. Though members of staff did sympathize with the man's frustration and did challenge the care manager, over time they gradually began to 'screen out' the resident's complaints, thereby adding to his frustration and anger. Since the man had been referred to the assessment unit for problems with anger and violent outbursts, this was not only profoundly disempowering, but clinically counter-productive.

In health services, discourses of ‘clinical needs' often take precedence over a person's immediate desires (eg van Hooren, Widdershoven, van den Borne \& Curfs, 2002), and it takes some semantic juggling to bring this into line with recent Department of Health guidance on implementing person-centred planning which suggests that choice should be the primary goal, or that the two agendas should be combined, as in the integration of Person-Centred Planning with Care Programme Approach assessments for those with challenging behaviour and mental health needs (Routledge \& Sanderson, 2001). This is difficult to achieve given the grey area where treatment and assessment currently reside in services for people with learning disabilities, in which behavioural regimes, drug treatment and intellectual assessments are administered with a little real consideration paid to issues of informed consent (see Edge, 2001, for a discussion of the legality of carrying out medical procedures without consent). Services charged with protecting and acting in the best interests of people with learning disabilities, by their very nature, rely upon the institutional capacity to overrule and act contrary to the wishes of the individual. Examples we observed included the promotion of continence in Care Plans, which in one service resulted in staff physically compelling residents to visit the toilet even when they protested, and more- 
or-less formal 'locked door' policies, which for the protection of service users limit their access to the world outside the units despite there being no legal basis for this.

We have also observed a range of preventive practices which were routinely carried out because staff believed they were necessary for good quality care, but which often were not. For example, in one unit residents were weighed monthly. Although some clearly did not want to be weighed, and made their resistance (and sometimes distress) clear, staff were observed to repeatedly encourage them onto the scales (Finlay, Antaki \& Walton, in press). When we discussed this with the staff team later, it appeared that none of them felt it was necessary for the health of the residents, but they did it 'because there's a chart'. Although no one knew who had originally devised the chart, they believed the Commision for Social Care Inspection (CSCI the organisation responsible for inspection of Social Care homes in the UK) inspections checked it, therefore it had to be filled in.

Inspection regimes are an important factor in the way in which services carry out their business. As Cocks and Cockram (1997) point out in their discussion of contradictions in legislation, health and safety rules with a protective focus 'may turn homes for people with learning disabilities into work places' (p237; see also Dowson, 1997). In one example from our research, a recent CSCI report on one residential home required that cleaning materials be stored in a locked cupboard, and noted that foods were put in the fridge without their contents and opening dates being properly labelled. Although residents were often responsible for doing their own laundry and preparing food, this meant they must now seek staff assistance to gain access to the washing powder and to properly label food before putting it in the fridge. In the same house there were five differently-coloured chopping boards, each one for a different type of food, and residents had to be supervised to ensure they choose the correct board. Clearly these requirements put obstacles in the way of the residents' independence which none of us face in our own homes. By complying with relevant regulations and procedures, the staff are compelled to follow procedures and practices that actively disempower the users of that service (for another example see Stancliffe et al, 2000). 
The problem with inspections from CSCI is that they encourage defensive practices by staff in the knowledge that the safety of the buildings, the health of the residents, the proper completion of 'paper trails', plans and charts are going to be checked. Assessing how much the residents are disempowered is a far more difficult business, and is approached only partially by checking whether people have 'person-centred plans' and by collecting verbal evidence from residents, families and staff. In many places, where residents are not able to report verbally and where families may be less concerned with choice than health and hygiene, CSCI inspections simply cannot assess this aspect of the quality of a service. The level of choice and control people in these services have can only be assessed by observing what goes on over a period of time in the mundane details of a person's life: can they choose to eat later?; can they decide to go to bed when they want?; can they help themselves to more tea?; do staff respond to them when they approach them for social interaction? Asking the staff whether this is generally the case, in our experience, does not necessarily provide reliable evidence.

To take this argument one step further, we have studied service-user meetings in a variety of residential and day services and found that when facilitated by a staff member these can be just as disempowering as other aspects of a person's life (Antaki et al, 2006; Jingree et al, 2006). Not only have we seen staff directing who can speak and when, what topics are appropriate for discussion, and which complaints and suggestions get taken seriously, but we have also seen how meetings can make decision-making far more difficult for some people who find it difficult to concentrate and respond in such settings. The irony is that the existence and minutes of such meetings are often produced as evidence by a service that it is listening to the voices of the service-users, and promoting self-advocacy. Other ways of promoting choice and control, which might be far more suitable for some people, such as talking to them over a period of days in a quiet place, do not produce such hard evidence of good practice, yet may be considerably more effective in achieving policy goals for some people.

\section{2) Attending to the small things}

When discussing choice and control, there is a danger of focusing on the bigger choices in a person's life: choosing a holiday, choosing where and with whom one 
lives; choosing activities or clubs outside the home, and so on. We might then neglect the much more frequent, everyday areas in which a person can experience empowerment and disempowerment. Although this is particularly important for people with multiple and severe impairments, it applies to all people with learning disabilities.

Let us consider one man who participated in our study. He did not communicate verbally, required assistance to walk, and had effective use of only one hand. For most of the day he would sit in a chair or a sofa in the group home in which he lived, watching what occurred around him. There appeared to be very little in his life over which he exercised control, except to cooperate or resist getting up when staff encouraged him, to offer his hand so that someone might hold it, or to choose what to look at in his immediate environment. Because he had extremely limited communication and needed assistance for almost every task of daily living, the staff did not think that there was much they could do to increase the level of control he had over his life. However, it was apparent from observation that the day was full of opportunities for him to exercise control, but they were so small and banal they were not seen by the staff as choice situations - they were seen instead as care situations. For example, we filmed one episode where he was sitting at a table with a small jug of coffee in front of him. He would pour a bit into his cup, drink, pour a bit more in, and so on. Although all staff knew he could do this himself, they did not routinely give him a jug; instead they would give him a full cup of coffee, and when he was finished they would take his cup from him. By simply providing him with a jug, and allowing him to take his own time, the amount of control he was able to exercise over drinking his coffee increased greatly. He could decide how full his cup was, when to refill, how many cups to drink. This type of control is crucial to a person with severe and multiple impairments, and if we pay attention to these types of details we have the opportunity of increasing people's levels of choice and control greatly without any extra resources.

In the same house, staff would routinely dish the food onto residents' plates at meattimes. One day they tried putting the food in serving bowls in the middle of the tables and allowing the residents to serve themselves. Suddenly the residents could decide the quantity of food they wanted, when they wanted to put it on their plates, what 
parts of a meal they did not want on their plates, and whether to have secondhelpings. Again, a simple change in practice allowed the residents to exercise a great deal more control over their lives. The reason staff gave for not doing it before was that the residents were not used to doing it; they feared people would take too much for themselves, would not know when to stop, or would break crockery. Rather than seeing this as an opportunity for empowerment, they saw it in terms of a perceived lack of competence. The staff needed to be reassured by the management and their colleagues that the benefits in terms of choice and independence were greater than the problems of a more uncontrolled dinner-time. Empowerment can be a messy business - we cannot fixate on goals of efficiency, 'good' sense, and tidiness if we really want to extend people's opportunities to exert themselves on the world.

We have given only two examples, but a day is filled with areas in which, with a small change in practice, a great deal of control can be given back to a person with severe learning disabilities without it actually costing anything. It just requires staff to recognize the opportunities when they arise.

\section{3) Communication difficulties}

It is acknowledged that in general we do not know enough about people with high support needs and how to offer them services which provide opportunities for choice and control (Learning Disabilities Taskforce, 2004). Staff face practical problems in offering or understanding preferences when people have limited language or comprehension (Edge, 2001; Grove, Bunning, Porter \& Olsson, 1999; Harris, 2003; Jenkinson, 1993; Puddicombe, 1995). For example, when understanding is uncertain and verbal communication limited, staff have to decide whether that person is really exercising a choice, is simply choosing what they know, or is responding to some feature of the options or context irrelevant to the choice being offered. When people have severe communication difficulties, there may be disagreement among supporters regarding how to interpret behaviours such as facial expressions, body movements, posture and vocalisations (Edge, 2001; Grove, Bunning, Porter \& Olsson, 1999). In contrast, policy guidance tends to present the expression of preference as unproblematic; the difficulties are thought to lie after the expression of preference - in the translation of preference into action. It is vital for policy to acknowledge that the promotion of choice and control is often characterized by uncertainty and 
communicative obstacles (Beamer \& Brooks, 2001; Edge, 2001; Puddicombe, 1995; see also Grove et al, 1999, 2000).

Suggestions for overcoming these sorts of problems do appear in the literature in the form of carefully controlled behavioural experiments in which people learn to use symbols, objects or microswitches to express preferences (eg Cooper \& Browder, 1998; Guess et al, 1985; Lancioni et al, 1998; Nozaki \& Mochizuki, 1995), or in recommendations to supporters to gather evidence to support interpretations (Edge, 2001; Grove et al, 2000; Puddicombe, 1995), and to treat behaviours as having meaning using developmental models (eg Grove et al, 1999). However, these strategies require either a degree of specialist knowledge or a culture of consistency, debate and evaluation which may be lacking in many services for people with severe communication difficulties. Such procedures were notably absent from some of the settings involved in our research.

We observed many situations in which staff found it difficult to ascertain what the person wanted. In a good number of cases, it appeared that aspects of the staff's behaviour created added confusion. For example, we observed one staff member open a multi-pack of crisps, remove two differently-flavoured packets and hold them out to a person, asking 'Which one do you want?'. The person being asked to decide could not read and did not speak, and, after a long pause, eventually took the packet that was held nearest to her. Given that the researchers did not recognize the flavours from the colours on the pack (one was 'lamb and mint'), it seemed likely that the woman choosing also did not. For this to really work as choice, more thought would have been required: for example by opening the packets so the person could sample each type, or, as a longer term strategy, teaching the person what each coloured packet tasted like. But at a glance it seemed as if a real choice had been offered.

In another home, in which the residents were more verbally able, staff went to great lengths to elicit preferences from those they supported. They suspected that a number of residents would habitually choose the last option offered them, and others would agree to suggestions without really understanding or attending to the content of the suggestion. As a result, the staff spent a lot of time checking people's answers: they would often rephrase questions several times before answers were finally accepted. 
Although this appeared to be an effective strategy for some residents, it led others to change their answers several times, suggesting that they took the follow-up questions as meaning their original answer was unsatisfactory.

A further pervasive practice in several homes was the reliance (and sometimes insistence) on verbal communication, much of which appeared too complex for the residents (for examples of this in other services see Bradshaw, 2001; Markova, 1991; McConkey, Morris \& Purcell, 1999; McConkey, Purcell \& Morris, 1999; Purcell, McConkey \& Morris, 2000). In one home in which the residents rarely communicated verbally, staff nevertheless used speech as their primary mode of interacting with them, often asking them questions and giving them options to which there was no evidence they could respond. Although this seemed a respectful way of offering support (after all, no one was sure quite how much the residents did understand), it would have been interesting to see how much easier life would have become for the residents if staff had had to think of non-verbal ways of interacting. Becoming used to developing interactions without speech (for example using Intensive Interaction Nind \& Hewitt, 2001 - or training staff in more sensitive communication - Dobson, Upadhyaya \& Stanley, 2002; Purcell et al, 2000) is a profoundly empowering way of working. In another home, staff would often miss relevant contributions that were made non-verbally because they were more 'tuned-in' to noticing verbal utterances, and would often ask resident questions verbally (for example about food) when it would have been just as easy (and much less confusing) to ascertain their preferences without speaking at all. All of these practices, we would argue, are disempowering since they put additional obstacles in the way of people with learning disabilities in their attempts to exert control over their environments.

\section{4) The pervasiveness of teaching}

There is a tension in service agendas which needs to be articulated - on the one hand services are to be person-centred (ie support designed around the preferences and needs of the individual) with the individual exercising choice and control, and on the other services are increasingly being encouraged to help develop the 'capacity' in their users to exercise control (e.g., SEU, 2005). Of course, services for people with learning disabilities have for many years been aiming to increase the independence and skills of those they support. The problem is that while both goals are laudable, in 
practice they often conflict: "the emphasis on instructional goals and objectives identified by staff is likely to be at the expense of client-initiated behaviours, including expression of choice and preferences” (Jenkinson, 1993, p370-1 ; see also Bannerman, Sheldon, Sherman \& Harchik, 1990). There is a particular danger that people with learning disabilities will always be seen as individuals who fall short on 'capacity' and therefore will always be put in the position of needing further training in some aspect of their lives. Supporters take on the role of teachers, and carrying out the daily tasks of living become teaching sessions.

Positioning a person with learning disabilities as someone to be instructed involves not only teaching practical skills, but also engaging in discussions about values and risks with the goal of 'developing' the person's understanding of the situation. The implicit goal may often be to bring the views or goals of a person into line with those favoured by their supporters, but through a dialogue about consequences rather than the supporter imposing a set of rules (e.g., van Hooren et al, 2002). Although this is an extremely difficult area, the potential for the supporter to exert their influence in subtle ways and make it appear as if the person with learning disabilities has made the choice themselves is enormous and must be acknowledged. In our research, instructional talk was a dominant feature of interactions between staff and residents when the latter had a reasonable degree of verbal ability (see Purcell et al, 2000 for a discussion of this issue), with supporters both testing the person's knowledge (eg plans; safety procedures; facts) as well as exerting influence through discussing obstacles and positive and negative outcomes of certain courses of action (eg Antaki et al, 2006, 2002; Jingree et al, 2006; Rapley, 2004)

However, conceiving of a person with learning disabilities as having a fixed identity can also be disempowering. In one of the units in our study, staff argued against changing their own practice on the basis that the residents' abilities were static. This included the (in)ability to do things for themselves and the (in)ability to exercise and understand choice. In one sense, this is a respectful way of operating, and conforms to Beamer and Brooks' (2001) suggestion 'that all people should be valued for who they are now, rather than what they might achieve, and support should be offered on that basis.” (p33). However, since support was then offered around these identities, and events arranged on a static conception of the residents' preferences, the result was that 
Promoting choice and control..

many opportunities in which residents could exercise choice or control were missed because routines and patterns of interaction were so well-established (for discussions of this issue see Edge, 2001, Puddicombe, 1995).

\section{Recommendations}

There has already been good work done in the literature on supported decisionmaking and person-centred approaches concerning how people can have their preferences registered and acted upon, and we will not reiterate these in detail here. Briefly, they include: having a range of people from outside the service engaged in supporting decision making (eg Beamer \& Brookes, 2001; Thompson, 2003); the importance of long-term knowledge concerning a person's subtle behaviours and how they reacted to the options on previous occasions (Beamer and Brooks, 2001; Edge, 2001; Puddicombe, 1995; Routledge \& Sanderson, 2001); the importance of collecting observations from a range of settings and supporters in order to ascertain the preferences of people with limited communicative abilities (eg Beamer \& Brooks, 2001; Edge, 2001; Grove et al, 1999, 2000; Sanderson, 1998); and of course the selfadvocacy movement (eg Aspis, 1997; Goodley, 2000).

We will restrict our recommendations to some things that can done to change disempowering cultures within individual services. While many organisations have decent programmes in which they take service-workers out of their place of work in order to provide them with training in person-centred approaches, we suggest that more immediate effects might be achieved by putting an independent observer into residential services, and allowing them to observe everyday life over a period of days (e.g. Dobson et al, 2002; Purcell et al, 2000). Because so much of what disempowers people with learning disabilities happens in the small, routine details of life, it can be hard for workers who have been immersed in the culture of a service to see it until it is pointed out to them. Since interactional practices are also central to empowerment and disempowerment, the use of video recording (with the appropriate attention to confidentiality and consent) can be invaluable in pointing out how ways of speaking can place obstacles in the way of a person's attempts to exert control over their lives. Of course, negotiation with staff over the role of the observer and the process is crucial for it to work effectively. 
In many cases, disempowering practices are rationalized with reference to the other agendas to which staff believe they have to orient (eg health and safety, provision of hard evidence for management/inspection); that is, disempowering practices can be defensive reactions to other service standards and agendas. In many cases, however, the 'good reasons' staff think they have for doing things in certain ways, or the rules they think are in operation, might actually be incorrect - but only when the practices are identified and discussed openly with senior staff can the process of 'myth-busting' take place. The same is true for rationalizations which prevent people from participation because their skills are deficient - it needs to be stressed (to both staff and families) that untidiness and a little bit of chaos are the natural results of services which promote empowerment and participation. Again, this type of process is best done inside the individual service working with the whole team around what actually happens from day-to-day, rather than taking individuals out of the service for training. In services which are chronically, profoundly disempowering, and there are still more of these around than there should be, often with long-established staff, strong (but not hostile) management is crucial to ensure that changes to routine practice are maintained.

This type of intervention encourages people to look at the small things in a person's life, moving services away from seeing choice and control as located primarily in the bigger decisions. This is an important issue for those responsible for inspecting residential services. Much of what we saw was oriented towards judgements that others might make of the home: was it clean? were food hygiene procedures in place? was there evidence that meetings had been held to ascertain residents' views? etc. CSCI inspections, while extremely important in maintaining standards, are currently poor at assessing whether choice and control are being promoted, and they should acknowledge that the ways services adjust to the inspections and reports might actually act against empowerment. The truth is that in many services we can only really judge whether residents have choice and control over their lives by spending a few days observing what happens. The answers are not in the filing system or the physical properties of the house, and the desire of services to provide evidence that choices have been offered might sometimes lead to situations which are not optimal for some residents’ participation (eg service-user meetings). 
Our final recommendation concerns the reliance on the vocal register that we see in residential services. For people with limited communicative abilities, or who prefer not to speak because their production of sound is indistinct, the natural inclination of staff to do their business verbally, and to celebrate and notice verbal utterances more than non-verbal utterances on the part of residents, can be extremely disempowering. This problem requires a more profound change to services but we believe it is necessary. This issue has already been flagged in a number of studies of staff communication (eg Bradshaw, 2001; Markova, 1991; McConkey, Morris \& Purcell, 1999; McConkey, Purcell \& Morris, 1999) and is admirably addressed by those advocating Intensive Interaction (eg Nind \& Hewitt, 2001), 'supported decision making' (eg Beamer \& Brooks, 2001), staff training in communication (e.g. Dobson et al, 2002; Purcell et al, 2000), and Goode’s (1994) work with deaf-blind children. However, the translation of these understandings into standard practice seems a long way off.

\section{Conclusions}

We need to recognize the difficulties poorly paid and often poorly trained staff face when we present choice and control as if they were straightforward goals. For the people in the units participating in our research, they were usually not. They often conflict with the many other values and goals of the services, and conflict with the ways in which staff 'do' being competent workers. Promoting empowerment is about changing what it means to be a good worker, changing what it means to have a wellrun day-service or home, and having the skills and strategies available to workers in order to realistically offer choice in situations where understandings and communication are at issue.

We should not underestimate the challenge. Disempowering discourses of care have been with us for a long time, and are bound up with layer upon layer of practice, policy, patterns of relationships, ways of speaking. Disempowerment is woven into the fabric of social care. The problem is that staff usually have the advantage when they interact with people with learning disabilities: the extra bit of knowledge, the privileged access to the organisation and its priorities, the suspicions about other views which might be brought to bear on the issue, the vocabulary and verbal fluency, and as a result it is hard not to dominate. It requires reining in their instinctive ways of 
interacting. Pointing out these problems is not to say there are not good and creative things being done in services. There certainly are. There are also bad things happening which are simply bad practice. But we need to recognize the gulf between the general goals of choice and empowerment at the policy level and the translation of this on the ground. Staff who support the choice agenda continually face practical, social and philosophical dilemmas and obstacles which they are not sure how to manage, and that this is not recognized at upper management and government levels can be a source or frustration and disillusionment. It is not enough to say services should be based around what service-users want. Staff know there is more at stake and that they are answerable to other agendas which often conflict with the choice agenda.

\section{Acknowledgements}

The research for this article was funded by ESRC grant number RES-148-25-0002. Thanks to the NHS trust in which the research took place, and the staff and residents involved

\section{References}

Antaki, C., Finlay, W.M.L., Sheridan, E., Jingree, T. \& Walton, C. (2006). Producing decisions in service-user groups for people with an intellectual disability: two contrasting facilitator styles. Mental Retardation, 44, 322-343.

Antaki, C., Young, N. \& Finlay, W.M.L. (2002). Shaping clients' answers: Departures from neutrality in care-staff interviews with people with a learning disability. Disability \& Society, 17 (4), 435-455.

Aspis, S. (1997). Self-Advocacy for people with learning disabilities: does it have a future? Disability and Society, 12, 647-654

Bannerman, D.J., Sheldon, J.B., Sherman, J.A. \& Harchik, A.E. (1990) Balancing the rights to habilitation with the right to personal liberties: the rights of people with developmental disabilities to eat too many doughnuts and take a nap. Journal of Applied Behavior Analysis, 23, 79-89. 
Promoting choice and control..

Beamer, S. \& Brookes, M. (2001) Making decisions: best practice and new ideas for supporting people with high support needs to make decisions. VIA: London

Bradshaw, J. (2001) Complexity of staff communication and reported level of understanding skills in adults with intellectual disability. Journal of Intellectual Disability Research, 45, 233-243

Cocks, E. \& Cockram, J. (1997) Empowerment and the limitations of formal human services and legislation. In P. Ramcharan, G. Roberts, G. Grant \& J. Borland (eds) Empowerment in everyday life: learning disability. London: Jessica Kingsley

Cooper, K.J. \& Browder, D.M. (1998) Enhancing choice and participation for adults with severe disabilities in community-based instruction. Journal of the Association for People with Severe Handicaps, 23, 252-260

Department of Health (2005) Independence, well-being and choice: Our vision for the future of social care for adults in England. Green Paper - Consultation Document.

Dobson, S., Upadhyaya, S. \& Stanley, B. (2002) Using an interdisciplinary approach to training to develop the quality of communication with adults with profound learning disabilities by care staff._International Journal of Language and Communication Disorders, 37, 41-57

Dowson, S. (1997). Empowerment within services: a comfortable delusion. In P. Ramcharan, G. Roberts, G. Grant \& J. Borland (eds) Empowerment in everyday life: learning disability. London: Jessica Kingsley

Edge, J. (2001) Who's in control?: decision-making by people with learning difficulties who have high support needs. London: Values Into Action. 
Finlay, W.M.L., Antaki, C. \& Walton, C. (in press) Saying no to the staff: an analysis of refusals in a care home for people with intellectual disabilities. Sociology of Health and Illness.

Goode, D. (1994) A World without Words: The Social Construction of Children Born Deaf-Blind. Philadelphia: Tempe University Press

Goodley, D. (2000). Self-advocacy in the lives of people with learning difficulties. Buckingham: Open University Press.

Grove, N., Bunning, K, Porter, J. \& Morgan, M. (2000) See what I mean: guidelines to aid understanding of communication by people with severe and profound learning disabilities. Wolverhampton: BILD.

Grove, N., Bunning, K, Porter, J. \& Olsson, C. (1999) See what I mean: interpreting the meaning of communication by people with severe and profound intellectual disabilities. Journal of Applied Research in Intellectual Disabilities, 12, 190-203

Guess, D., Benson, H.A. \& Siegel-Causey, E. (1985) Concepts and issues related to choice-making and autonomy among persons with severe disabilities. Journal of the Association for Persons with Severe Handicaps, 10, 79-86

Harris, J. (2003) Time to make up your mind: why choosing is difficult. British Journal of Learning Disabilities, 31, 3-8.

HM Government (2005) The Government's annual report on Learning Disability, 2005. Valuing People: making things better. TSO: Norwich

Hudson, B. (1993) Michael Lipsky and street-level bureaucracy: a neglected perspective. In M. Hill (ed) The Policy Process: A reader. Harvester Wheatsheaf: Hemel Hempstead. 
Jenkinson, J.C. (1993) Who shall decide? The relevance of theory and research to decision-making by people with an intellectual disability. Disability, Handicap and Society, 8, 361-375

Jenkinson, J., Copeland, C., Drivas, B., Scoon, H., Yap, M.L. (1992) Decisionmaking by community residents with an intellectual disability. Australia and New Zealand Journal of Developmental Disabilities, 18, 1-8.

Jingree, T., Finlay, W.M.L. \& Antaki, C. (2006). Empowering words, disempowering actions. Journal of Intellectual Disability Research, 50, 212-226

Kinsella, P. (2000) What are the barriers in relation to Person Centred Planning? York: Joseph Rowntree Foundation

Lancioni, G.E., O’Reilly, M.F. \& Emerson, E. (1996) A review of choice research with people with severe and profound developmental disabilities. Research in Developmental Disabilities, 17, 391-411

Learning Disability Taskforce (2004) Rights, independence, choice and inclusion. Learning Disability Taskforce; London

Lipsky, M. (1993) Street-level bureaucracy: an introduction. In M. Hill (ed) The Policy Process: A reader. Harvester Wheatsheaf: Hemel Hempstead.

Marková, I. (1991) Asymmetries in group conversations between a tutor and people with learning difficulties. In Marková, I and Foppa, K. (Eds) Asymmetries in Dialogue. Hemel Hempstead, Harvester Wheatsheaf.

McConkey, R.M., Morris, I. \& Purcell, M. (1999) Communications between staff and adults with intellectual disabilities in naturally occurring settings. Journal of Intellectual Disability Research, 43, 194-205 
McConkey, R.M., Purcell, M. \& Morris, I. (1999) Staff perceptions of communication with a partner who is intellectually disabled. Journal of Applied Research in Intellectual Disabilities, 12, 204-210

Nind, M. \& Hewett, D. (2001) A practical guide to intensive interaction. Kidderminster: BILD Publications.

Nozaki, K. \& Mochizuki, A. (1995) Assessing choice making of a person with profound disabilities: a preliminary analysis. Journal of the Association for People with Severe Handicaps, 20, 196-201

Prime Minister's Strategy Unit (2005) Improving the life chances of disabled people.

Puddicombe, B. (1995) Face to face: communicating with people who do not use language. London: Values Into Action.

Purcell, M., McConkey, R. \& Morris, I. (2000) Staff communication with people with intellectual disabilities: the impact of a work-based training programme. International Journal of Language and Communication Disorders, 35, 147-158

Rawlings, M., Dowse, L. \& Shaddock, A. (1995) Increasing the involvement of people with an intellectual disability in choice making situations: a practical approach. International Journal of Disability, Development and Education, 42, 137-153

Routledge, M. \& Sanderson, H. (2001). Planning with people: towards personcentred approaches. Guidance for Implementation Groups. Department of Health; London

Sanderson, H. (1998) A say in my future: involving people with profound and multiple disabilities in person centred planning. In L. Ward (ed) Innovations in advocacy and empowerment for people with intellectual disabilities. Chorley: Lisieux-Hall Publications 
Promoting choice and control..

Social Exclusion Unit (2005) Improving services, improving lives: evidence and key themes. Interim report. Office of the Deputy Prime Minister; London.

Stalker, K. \& Harris, P. (1998) The exercise of choice by adults with intellectual disabilities: a literature review. Journal of Applied Research in Intellectual Disabilities, 11, 60-76

Stancliffe, R.J., Abery, B.H. \& Smith, J. (2000) Personal control and the ecology of community living settings: beyond living-unit size and type. American Journal on Mental Retardation, 105, 431-454

Swift, P. (2005) Organisational factors influencing the effectiveness of person centred planning. In J. Robertson et al (eds) The impact of person centred planning. Lancaster University: Institute for Health Research.

Thompson, S.A. (2003) Subversive political praxis: supporting choice, power and control for people with learning difficulties. Disability and Society, 18, 719-736.

van Hooren, R.H., Widdershoven, G.A.M., van den Borne, H.W. \& Curfs, L.M.G. (2002) Autonomy and intellectual disability: the case of prevention of obesity in Prader-Willi syndrome. Journal of Intellectual Disability Research, 46, 560-568 